\title{
Flavonoids and intestinal cancers
}

\author{
Roberto Pierini, Jennifer M. Gee, Nigel J. Belshaw and Ian T. Johnson* \\ Institute of Food Research, Norwich Research Park, Colney, Norwich NR4 7UA, UK
}

Cancers of the gastrointestinal tract are amongst the most common causes of death from cancer, but there is substantial variation in incidence across populations. This is consistent with a major causative role for diet. There is convincing evidence that fruits and vegetables protect against cancers of the upper alimentary tract and the large bowel, and this has focused attention on biologically active phytochemicals, and on flavonoids in particular. Many flavonoids exert anticarcinogenic effects in vitro and in animals, and many of these effects occur via signalling pathways known to be important in the pathogenesis of colorectal, gastric and oesophageal cancers. However dietary flavonoid intakes are generally low and their metabolism in humans is extremely complex. The advent of new post-genomic technologies will do much to address these problems by making it possible to monitor patterns of gene expression in humans to provide essential molecular biomarkers of early disease. By combining such data with knowledge of the dietary exposure and bioavailability of the most effective compounds it will be possible to predict the most effective dietary sources and to properly evaluate the potential role of flavonoids in clinical nutrition.

Colon: Stomach: Oesophagus: Quercetin: Neoplasia

Neoplasms of the alimentary tract are amongst the most common of all cancers, but they show striking variability in incidence, both across geographical boundaries, and within populations undergoing social and environmental changes ${ }^{(1)}$. In its review of diet and cancer published in 1997. The World Cancer Research $^{(2)}$ found "convincing" evidence for protective effects of fruits and vegetables against cancers of the upper aerophagic tract, stomach and lung, and of vegetables against cancers of the colon and rectum, and there is a continuing consensus in favour of a protective role for fruits and vegetables against cancers of the alimentary tract. This review is concerned with the hypothesis that one particular class of phytochemicals, the flavonoids, exert protective effects against these cancers. Flavonoids occur very widely in plants used as human foods ${ }^{(3)}$, and much of the colour, flavour and aroma of chocolate, tea, coffee and wine reflects the complex variety of phenolic compounds that they contain. Most of our current knowledge about these compounds has been obtained through the use of classical cell biology and biochemistry methods, but there is now increasing interest in the use of nutrigenomics to deepen our understanding of these and other phytochemicals ${ }^{(4-7)}$, and one important goal of this review is to explore the potential for using this approach to explore the anticarcinogenic effects of flavonoids in the gut.

\section{Flavonoids as anticarcinogens}

Flavonoids are amongst the most thoroughly studied anticarcinogens, but much of the evidence has been derived from in vitro studies, using compounds such as quercetin aglycone, which is rarely found in the diet, and never in the human body.
Under physiological conditions, a relatively small fraction of the quercetin glycosides found in foods is hydrolysed at the intestinal surface, and the released aglycone is absorbed and rapidly metabolised, largely to glucuronides, which are then transferred to the circulation ${ }^{(8)}$. Unabsorbed polyphenols eventually become available for bacterial fermentation, yielding a mixture of phenolic acids in the colon ${ }^{(9)}$. This section is a general overview of interactions between flavonoids and potentially anticarcinogenic mechanisms.

\section{Modulation of carcinogen metabolism}

The first lines of defence against food- and air-borne carcinogens and toxins are the phase I and phase II metabolic enzymes expressed in the gut, liver and lung. Phase I metabolism involves oxidation, reduction and hydrolysis, principally via the cytochrome $\mathrm{P} 450$ enzymes ${ }^{(10)}$. The reaction products are often highly reactive genotoxins that form substrates for phase II enzymes such as glutathione $S$-transferase (GST), NAD:quinone reductase and $\gamma$-glutamylcysteine synthetase. Phase II products are water-soluble, less reactive conjugates, which are readily excreted via the kidneys or in bile. Phase I and II enzymes are inducible by compounds that interact with the xenobiotic response element (XRE) and the antioxidant response element (ARE) respectively. Those that interact primarily with the ARE, and hence selectively induce phase II enzymes without simultaneously inducing phase I activity, are often potent anticarcinogens ${ }^{(11)}$. Amongst the flavonoids, the most actively investigated are the flavanols, including epigallocatechin gallate (EGCG), the putative principal anticarcinogenic component of green tea ${ }^{(12)}$.

Abbreviations: ARE, antioxidant response element; CDK, cyclin dependent kinase; COX, cyclo-oxygenase; EC, epicatechin; EGC, (-)-epigallocatechin; ECG, (-)-epicatechin-3-gallate; EGCG, epigallocatechin gallate; GERD, gastro-oesophageal reflux disease; GPx, glutathione peroxidase; GST, glutathione $S$-transferase; IKK, ІкB kinase; NF-кB, nuclear transcription factor кB; OA, oesophageal adenocarcinoma; OSCC, oesophageal squamous cell carcinoma; PAR, population attributed risk; XRE, xenobiotic response element.

* Corresponding author: Dr Ian T. Johnson, fax + 441603 255288, email ian.johnson@bbsrc.ac.uk 


\section{Modulation of inflammatory pathways}

Inflammation is a risk-factor for many types of cancer, and it is well established that chronic use of anti-inflammatory drugs such as aspirin reduces the risk of cancers of the colon ${ }^{(13)}$ and oesophagus $^{(14,15)}$. This has established that cancers of the gastrointestinal tract are susceptible to chemoprevention, and prompted a search for natural food-borne anti-inflammatory factors. One important focus of interest is compounds that interact with nuclear transcription factor $\kappa \mathrm{B}(\mathrm{NF}-\kappa \mathrm{B})$. In its inactive form NF- $\mathrm{KB}$ is present in the cytoplasm as a complex with IкB. Activation of $N F-\kappa B$ is brought about by $І \kappa B$ kinase (IKK)-dependent phosphorylation, ubiquitination and proteolysis of $\mathrm{I} \kappa \mathrm{B}$, which frees $\mathrm{NF}-\kappa \mathrm{B}$ to enter the nucleus and bind to the $\kappa \mathrm{B}$ sequence motif in DNA. NF- $\kappa \mathrm{B}$ is involved in the regulation of a large number of genes but is particularly important as an up-regulator of the inflammatory response. Phenolic substances found in plant foods and beverages inhibit NF- $\mathrm{BB}$ activation at various stages. Curcumin for example suppresses TNF-induced activation of $\mathrm{IKK}^{(16)}$, whereas caffeic acid phenethyl ester specifically prevents binding of NF- $\kappa \mathrm{B}$ to its target DNA sequence ${ }^{(17)}$.

Another important pro-inflammatory mechanism potentially susceptible to modulation by flavonoids is that mediated by cyclooxygenase (prostaglandin $\mathrm{H}$ synthase). This enzyme system comprises two distinct isoforms; COX-1 produces prostaglandins essential to platelet aggregation and the maintenance of gastric mucosal integrity, and is constitutively expressed, whereas COX-2 is induced by tumour promoters and endogenous cytokines, and produces prostaglandins involved in inflammation. Many flavonoids have been shown to be COX-2 enzyme inhibitors ${ }^{(18)}$ and some, including apigenin, chrysin, and kaempferol, can suppress COX-2 transcription $^{(19)}$.

\section{Regulation of cell proliferation and apoptosis}

One of the most important pathways involved in the regulation of cell proliferation in both gastric and colorectal epithelia is that involving the intracellular protein $\beta$-catenin ${ }^{(20)}$. In normal epithelial cells there is a relatively large and stable pool of $\beta$-catenin immobilised by interactions with cytoskeletal proteins, and a small labile pool in the cytoplasm. However in cancer cells the balance is altered in favour of the cytoplasmic pool because the regulatory mechanism for $\beta$-catenin is disrupted by various mutations or epigenetic events $^{(21)}$. Modulation of the $\beta$-catenin system occurs through the so-called canonical Wnt-signalling pathway. The Wnt proteins are cysteine-rich glycoproteins are released into the extracellular milieu where they interact either with membrane receptors of target cells ${ }^{(22)}$. Binding of Wnt to its membrane receptors initiates an intracellular signalling event that causes destabilisation of the $\beta$-catenin destruction complex, accumulation of $\beta$-catenin in the cytoplasm and increased levels of the $\beta$-catenin in the nucleus, where it leads to the transcription of a variety of pro-mitotic effector genes including C-myc, cyclin-D1, c-jun, COX-2. Wnt signalling plays an important role in gut formation during mammalian embryogenesis, and contributes to the maintenance of normal gut homeostasis in the adult. The common food-borne flavonoid quercetin ${ }^{(23)}$, which suppresses colorectal crypt cell proliferation in the rat in vivo ${ }^{(24)}$, has been shown to inhibit the $\beta$-catenin pathway in vitro ${ }^{(25,26)}$.

The survival of most cancer cells depends critically upon their ability to divide continuously, and to evade apoptosis. A variety of different flavonoids have been shown to inhibit proliferation and enhance apoptosis in vitro ${ }^{(27-29)}$. Compounds that enhance apoptosis at biologically achievable concentrations in vivo are of great interest both as chemotherapeutic drugs, and as chemoprotective agents, particularly if they act selectively against transformed cells ${ }^{(30)}$. However, despite the great variety of naturally occurring compounds shown to be active in vitro, it has proven much more difficult to establish that food-borne flavonoids increase apoptosis in animals or humans.

\section{Flavonoids and colorectal carcinoma}

There is moderately good epidemiological evidence for protective effects of fruits and vegetables against colorectal cancer, and this has focused attention on the possibility that these effects might be due to the biological activity of flavonoids acting at one or more stages in the development of the disease. Most colorectal carcinomas in developed countries develop from initially benign adenomatous polyps via the adenoma-carcinoma sequence ${ }^{(31)}$. This step-wise pathway involves both morphological changes associated with the emergence and growth of the localised lesion, and a progressive disruption of the genome, including acquisition of somatic mutations ${ }^{(32)}$ and silencing of genes through changes to the epigenetic marks regulating gene expression. The most widely studied epigenetic mechanism is the hypermethylation of the cytosine residues in $\mathrm{CpG}$-rich sequences (CpG-islands) located within the promoter regions of expressed genes ${ }^{(33)}$. These sequences are normally unmethylated, but once methylated during the development of cancer they become progressively silenced by mechanisms involving recruitment of protein complexes, compaction of adjacent chromatin and suppressed transcription ${ }^{(34)}$. Cancers of the alimentary tract exhibit more aberrant methylation than cancers of the lung, ovary and bladder ${ }^{(35)}$, and silencing of DNA-repair and tumoursuppressor genes makes a major contribution to the genomic dysfunction associated with colorectal carcinoma ${ }^{(36)}$.

Although food-borne flavonoids undoubtedly modulate molecular signals involved in the development of colorectal cancer under experimental conditions, the concentrations of these compounds in food are relatively low and there is little epidemiological evidence to support a protective role against cancer for flavonoids derived from food ${ }^{(37)}$. There is better evidence however that flavonoids from tea may play a protective role at the population level. Tea is an infusion prepared from the leaves of the plant Camellia sinensis and is one of the major sources of flavonoids in many western and oriental diets. The polyphenolic constituents of the tea infusion depend upon the processing of the leaves. Green tea is steamed immediately after picking to denature the polyphenol oxidases in the leaves, and hence stabilise the low molecular weight compounds, which are principally the catechins: epicatechin (EC), (-)-epigallocatechin gallate (EGCG), (-)-epigallocatechin (EGC) and (-)-epicatechin-3-gallate (ECG). In contrast, black tea and Oolong tea are crushed and allowed to oxidise prior to drying. This leads 
to polymerisation of the polyphenols, forming high levels of theaflavins and thearubigens, with a corresponding reduction in the levels of catechins.

Black tea polyphenol consumption shows protective effects against oxidative DNA damage to the colon in animal models ${ }^{(38)}$, and black tea significantly reduced the formation of aberrant crypt foci in a rats with preneoplastic lesions induced by azoxymethane. In the early stages GST and glutathione peroxidase (GPx) gene expression were upregulated, suggesting that black tea effects might be mediated by antioxidative mechanisms ${ }^{(39)}$. EGCG reduces the invasive activity and growth of murine colon 26-L5 cell line in vitro, and significantly reduced lung metastasis in BALB/c mice inoculated with $26-\mathrm{L} 5$ cells $^{(40)}$.

Orner et al. ${ }^{(41)}$ used the Apc(min) mouse model to compare the anti-tumorigenic effects of green tea with those of "white" tea, a product that contains even higher levels of flavonoids. Mice treated with both types of tea had significantly lower numbers of tumours than the untreated controls, and there were significant reductions in beta-catenin and beta- catenin/ Tcf-4 regulated proteins Cyclin $\mathrm{D}^{(1)}$ and c-Jun in the apparently normal intestines of mice treated with both white tea and sulindac. Similarly, Ju et al, working with Apc(min) mice showed that treatment with EGCG reduced the high levels of nuclear beta-catenin in these mice, and inhibited aberrant gene expression ${ }^{(42)}$.

A rigorous meta-analysis of epidemiological studies on the relationship between tea consumption and colorectal cancer was recently published by Sun et al. ${ }^{(43)}$, who identified 25 papers describing studies conducted in European, North American and Asian populations. Eight studies provided evidence for a protective effect of green tea such that the highest had an odds ratio for colon cancer of 0.82 (95\% CI 0.69-0.98) compared to the lowest consumers. There was no evidence of a protective effect against rectal cancer, nor was there evidence for a protective effect of black tea against cancer at either site. The same group has recently compared urinary metabolites of tea polyphenols with subsequent risk of colorectal during 16 years of follow-up in a cohort of 18244 Chinese men. Subjects with higher levels of EGC and $4^{\prime}$-0-methyl-EGC in their urine had a significantly lower risk of colon cancer, but not of rectal cancer.

Wine is another commonly consumed beverage capable of delivering high concentrations of polyphenols to the alimentary tract. Polyphenols derived from red wine reduced colon tumour yield and oxidative DNA damage, induced in rat colon mucosa by the model carcinogen 1,2-dimethylhydrazine. Functional pathway analysis carried out on microarray gene expression data showed that wine polyphenol consumption down-regulated the inflammatory response and steroid metabolism ${ }^{(44)}$

\section{Flavonoids and gastric carcinoma}

Two distinct histological sub-types of gastric cancer have been identified: intestinal-type and diffuse-type ${ }^{(45)}$. Unlike colorectal cancer, the incidence of gastric cancer is in worldwide decline, with the sharpest reductions over the last few decades occurring in the industrialised world. However, whereas distal, intestinal-type gastric cancers have tended to decline in industrialised countries, the incidence of proximal cancers of the gastric cardia has increased recently ${ }^{(46)}$. The bacterium Helicobacter pylori is the principal known risk factor for gastric carcinogenesis ${ }^{(47)}$. Infection rates are inversely associated with affluence, both within and between countries, but the interaction between $H$. pylori and other environmental factors remains to be established.

As with colorectal cancer, a multistage sequence in the development of intestinal-type gastric carcinoma has been identified, beginning with chronic gastritis, and proceeding to mucosal atrophy, and intestinal metaplasia ${ }^{(48)}$. The latter stage involves the development of a cellular phenotype similar to that of the intestine, which is associated with the ectopic expression of the protein CDX2, a transcription factor normally expressed by intestinal epithelial cells. The final stage of malignant transformation leads to the appearance of a discreet tumour with glandular histology. $A P C$ and $K-R A S$ mutations do occur in some tumours, and methylation of the $\mathrm{CpG}$-island of tumour-suppressor and DNA-repair genes is widely reported. Diffuse-type gastric cancers do not form discreet lesions but develop as small groups of cells distributed through the mucosal tissue. This pathway is associated specifically with mutations or epigenetic silencing of E-cadherin. $H$. pylori infection predisposes to both types of gastric cancer $^{(49)}$, but its mechanism of action is best understood in the case of chronic gastritis-atrophy-metaplasia sequence of intestinal-type carcinogenesis. Recently Ruggiero et al. ${ }^{(50)}$ reported that certain polyphenols ameliorate the adverse effects of $H$. pylori infection on the gastric mucosa in a mouse model, probably by exerting antitoxic activity.

As with colorectal cancer, there are numerous studies showing that a variety of flavonoids inhibit the proliferation of gastric carcinoma cells ${ }^{(51)}$ and induce apoptosis ${ }^{(52)}$ but relatively little evidence for protective effects of flavonoids at the population level. Sun et al. ${ }^{(53)}$ conducted a nested case-control study to explore the relationship between urinary markers of exposure to tea polyphenols and subsequent risk of gastric cancer in a cohort of over 18000 Chinese men. There was a strong inverse association between urinary EGC and risk of gastric and oesophageal cancer (odds ratio 0.52 , 95\% CI 0.28-0.97), which suggests that tea polyphenols may exert anticarcinogenic effects in this part of the gut, as well as the colon. It is less clear whether similar protective effects of polyphenols occur in populations consuming conventional Western diets. Lagiou et al. ${ }^{(54)}$ examined the relationship between dietary intake of six classes of flavonoids (flavanones, flavan-3-ols, flavonols, flavones, anthocyanidins and isoflavones) and vitamin $\mathrm{C}$ in the aetiology of stomach cancer in a small case-control study conducted in Greece, and observed a statistically significant protective effect of flavanones. They commented that this might account for the apparently beneficial effects of fruit reported in some epidemiological studies, but given the small size of the study and the difficulty of estimating flavonoid intakes from dietary records, further research would be needed to explore this possibility.

It is worth noting that flavonoids also exert mutagenic effects in vitro and for a long period before the growth of interest in phytochemicals as anticarcinogens they were regarded as possible carcinogens. Gaspar et al. ${ }^{(55)}$ used the Ames test to show that the mutagenicity of red wines 
correlated well with their quercetin content, but it has not since been established that these adverse effects are directly relevant to human health.

\section{Flavonoids and oesophageal carcinoma}

Oesophageal cancer occurs in two histological subtypes, squamous cell carcinoma (OSCC), and adenocarcinoma (OA). Overall the disease occurs somewhat more frequently in less developed countries than in the industrialised west ${ }^{(56)}$ but some of the steepest contrasts in reported incidence occur within countries in Africa and Asia, where squamous carcinoma is the predominant form. Such variations appear to be associated with a combination of micronutrient deficiencies and high exposure to environmental mutagens ${ }^{(57)}$. Over the last 30 years, the incidence of OSCC has decreased in many industrialised countries, whereas an unexplained increase in the rates of $\mathrm{OA}$ has occurred in the United States and Western Europe ${ }^{(58)}$

Typically, adenocarcinoma develops from Barrett's oesophagus, an intestinal-type metaplasia that replaces the normal squamous mucosa in the lower third of the oesophagus ${ }^{(59)}$, apparently in response to chronic irritation by gastric reflux. In $10-15 \%$ of cases there is progression via lowand high-grade dysplasia to adenocarcinoma, accompanied by somatic mutations of genes including $p 53$ and $K-R A S$, chromosomal losses and aneuploidy, and methylation of the CpG-islands of APC, CDKN2A, ESR1 and E-Cadherin ${ }^{(60)}$.

Gastro-oesophageal reflux disease (GERD) is the strongest identified risk-factor for $\mathrm{OA}^{(61)}$, and the disease shows a strong positive relationship with obesity ${ }^{(62)}$. Several epidemiological studies show evidence for an inverse correlation between fruit and vegetable consumption and risk of both $\mathrm{OA}$ and $\mathrm{OSCC}^{(63,64)}$. Engel and colleagues estimated that the population attributable risk (PAR) associated with low fruit and vegetable consumption was of $29 \%$ for OSCC and $15 \%$ for $\mathrm{OA}^{(65)}$.

Aspirin and other synthetic COX-2 enzyme inhibitors are protective against $\mathrm{OA}^{(15)}$. A number of flavonoids are COX2 inhibitors $^{(18)}$ and some (e.g. apigenin, chrysin, and kaempferol) can suppress $C O X-2$ transcription by mechanisms that include activation of the peroxisome proliferator-activated receptor (PPAR) gamma transcription factor ${ }^{(19)}$, and inhibition of $\mathrm{NF}-\kappa \mathrm{B}$ expression ${ }^{(66)}$. $C O X-2$ transcription is inhibited in vitro not just by quercetin aglycone, but also by the metabolites quercetin 3-glucuronide, quercetin 3 -sulphate, and $3^{\prime}$-methylquercetin 3-glucuronide. These compounds are found in human plasma, and both quercetin and quercetin $3^{\prime}$-sulphate also inhibit COX-2 enzyme activity ${ }^{(67)}$. Quercetin aglycone inhibits COX-2 expression and induces apoptosis in the oesophageal adenocarcinoma cell line OE33 in vitro ${ }^{(68)}$.

EGCG is another flavonoid which is of particular interest in the context or oesophageal cancer. In studies carried out on $\mathrm{N}$ nitrosomethylbenzylamine (NMBA)-induced OSCC in rats, EGCG reduced the incidence of tumours in a dose-dependent manner, and significantly down-regulated the gene expression of both cyclin D1 and COX-2 $2^{(69)}$. Perhaps the most intriguing property of EGCG in this context is its ability to inhibit DNA methyltransferase (DNMT) activity. Epigenetic silencing of genes involved in cell cycle regulation, like $p 16$ and retinoic acid receptor beta $(R A R \beta)$, and DNA repair, like
O6-methylguanine-DNA methyltransferase (MGMT) and human mutL homologue $1(h M L H 1)$, are important events in OSCC development ${ }^{(70)}$. The EGCG-induced inhibition of DNMT reversed the methylation status of the promoters of these genes in an OSCC cell line leading to their reexpression $^{(71)}$. Similar results were obtained using the same in vitro model treated with genistein, a soy-derived isoflavone ${ }^{(72)}$. However the inhibition of DNMT1 activity by genistein was relatively weak, suggesting that it might act by a different pathway ${ }^{(72)}$. Other flavonoids (myricetin, quercetin, hesperetin, naringenin, epigenin and luteolin) have also been shown to inhibit DNMT activity in OSCC nuclear extracts, although less efficiently than EGCG.

Flavopiridol is a synthetic flavone identical to one obtained from the Indian plant Dysoxylum binectiferum, which has attracted a great deal of attention as a possible chemotherapeutic agent for the treatment of gastrointestinal and other solid tumours. The primary action of flavopiridol is to inhibit cyclin dependent kinases (CDK) 1,2 and $4^{(73)}$. Indeed it is the first pan-cyclin-dependent kinase (CDK) inhibitor to enter clinical trials. Flavopiridol has been shown to induce G1 or G2/M cell cycle arrest and apoptosis and reduce protein levels of cyclin D1 and Retinoblastoma (Rb), which are crucial regulators of $\mathrm{G} 0 / \mathrm{G} 1$ cell cycle checkpoint, in several $\mathrm{OA}$ and OSCC cell lines ${ }^{(74)}$. Promising results have also been obtained using in vivo models of OA and OSCC. Unfortunately however, flavopiridol has adverse side effects that appear to be due to its ability to act as a general suppressor of gene transcription ${ }^{(75)}$. Some recent studies showed that flavopiridol treatment enhanced the sensitivity to radiation of $\mathrm{OA}$ cell lines, and xenografts in nude mice ${ }^{(76,77)}$. Further investigations are needed to assess whether flavopiridol can be used safely in combination with other therapeutic agents or radiation for clinical purposes.

\section{Conclusion}

There is substantial evidence to show that flavonoids from foods and beverages exert anticarcinogenic effects in vitro against tumours derived from epithelial cells of the alimentary tract, and that they modulate molecular signalling pathways known to be involved in human disease. There is also emerging evidence that certain flavonoid-rich foods, and particularly beverages, are associated with a reduced risk of disease at the population level. However it is difficult to prove that these different observations are causally linked, partly because of the relatively low flavonoid intakes and complexity of metabolism in humans in vivo, and partly because of the lack of adequate molecular biomarkers with which to monitor the earliest stages of disease development in humans. The advent of new post-genomic technologies can do much to address these problems. Improved analytical procedures are helping to clarify both the metabolic fate of ingested flavonoids in humans ${ }^{(78)}$, and their bioavailability ${ }^{(79)}$. Even more importantly, by characterising the profiles of genes and proteins that are modified in target tissues during the earliest stages of disease, and determining the extent to which these patterns of gene expression can be modulated by flavonoids, the post-genomic technologies enable us to develop rigorous molecular models for the effects of these compounds on the mucosa of the alimentary tract. Finally, by combining 
these data with knowledge of the bioavailability of the most effective compounds and their occurrence in food, it will become possible to predict which dietary sources offer the best protection against the major gastrointestinal cancers, and to properly evaluate the potential role of flavonoids in clinical nutrition ${ }^{(80)}$.

\section{Acknowledgements}

The publication of this paper was made possible by the financial support of the European Co-operation in the field of Scientific and Technical (COST) Research Action 926 "Impact of new technologies on the health benefits and safety of bioactive plant compounds" (2004-2008). The authors had no conflicts of interest to disclose.

\section{References}

1. Parkin DM, Bray F, Ferlay J \& Pisani P (2005) Global cancer statistics, 2002. CA Cancer J Clin 55, 74-108.

2. World Cancer Research Fund (1997) Food, Nutrition and the Prevention of Cancer: a Global Perspective, pp. 216-251. Washington DC: American Institute for Cancer Research.

3. Hollman PCH \& Arts ICW (2000) In Flavonols, flavones and flavanols - nature, occurrence and dietary burden. J Sci Food Agric 80, 1081-1093.

4. Corthesy-Theulaz I, den Dunnen JT, Ferre P, Geurts JM, Muller M, van Belzen N \& van Ommen B (2005) Nutrigenomics: the impact of biomics technology on nutrition research. Ann Nutr Metab 49, 355-365.

5. Davis CD \& Hord NG (2005) Nutritional "omics" technologies for elucidating the role(s) of bioactive food components in colon cancer prevention. J Nutr 135, 2694-2697.

6. Mariman EC (2006) Nutrigenomics and nutrigenetics: the 'omics' revolution in nutritional science. Biotechnol Appl Biochem 44, 119-128.

7. Fuchs D, Winkelmann I, Johnson IT, Mariman E, Wenzel U \& Daniel H (2005) Proteomics in nutrition research: principles, technologies and applications. Br J Nutr 94, 302-314.

8. Day AJ, Gee JM, DuPont MS, Johnson IT \& Williamson G (2003) Absorption of quercetin-3-glucoside and quercetin$4^{\prime}$-glucoside in the rat small intestine: the role of lactase phlorizin hydrolase and the sodium-dependent glucose transporter. Biochem Pharmacol 65, 1199-1206.

9. Scalbert A, Morand C, Manach C \& Remesy C (2002) Absorption and metabolism of polyphenols in the gut and impact on health. Biomed Pharmacother 56, 276-282.

10. Nelson DR, Kamataki T, Waxman DJ, Guengerich FP, Estabrook RW, Feyereisen R, Gonzalez FJ, Coon MJ, Gunsalus IC, Gotoh O, et al. (1993) The P450 superfamily: update on new sequences, gene mapping, accession numbers, early trivial names of enzymes, and nomenclature. DNA Cell Biol 12, 1-51.

11. Prochaska HJ \& Talalay P (1988) Regulatory mechanisms of monofunctional and bifunctional anticarcinogenic enzyme inducers in murine liver. Cancer Res 48, 4776-4782.

12. Chou FP, Chu YC, Hsu JD, Chiang HC \& Wang CJ (2000) Specific induction of glutathione S-transferase GSTM2 subunit expression by epigallocatechin gallate in rat liver. Biochem Pharmacol 60, 643-650

13. Chan AT, Giovannucci EL, Meyerhardt JA, Schernhammer ES, Curhan GC \& Fuchs CS (2005) Long-term use of aspirin and nonsteroidal anti-inflammatory drugs and risk of colorectal cancer. JAMA 294, 914-923.

14. Ranka S, Gee JM, Johnson IT, Skinner J, Hart AR \& Rhodes M (2006) Non-Steroidal Anti-Inflammatory Drugs, Lower
Oesophageal Sphincter-Relaxing Drugs and Oesophageal Cancer. A Case-Control Study. Digestion 74, 109-115.

15. Vaughan TL, Dong LM, Blount PL, Ayub K, Odze RD, Sanchez CA, Rabinovitch PS \& Reid BJ (2005) Non-steroidal anti-inflammatory drugs and risk of neoplastic progression in Barrett's oesophagus: a prospective study. Lancet Oncol 6, 945-952.

16. Singh S \& Aggarwal BB (1995) Activation of transcription factor NF-kappa B is suppressed by curcumin (diferuloylmethane). J Biol Chem 270, 24995-25000.

17. Natarajan K, Singh S, Burke TR Jr, Grunberger D \& Aggarwal BB (1996) Caffeic acid phenethyl ester is a potent and specific inhibitor of activation of nuclear transcription factor NF-kappa B. Proc Natl Acad Sci U S A 93, 9090-9095.

18. Baumann J, von Bruchhausen F \& Wurm G (1980) Flavonoids and related compounds as inhibition of arachidonic acid peroxidation. Prostaglandins 20, 627-639.

19. Liang YC, Tsai SH, Tsai DC, Lin-Shiau SY \& Lin JK (2001) Suppression of inducible cyclooxygenase and nitric oxide synthase through activation of peroxisome proliferator-activated receptor-gamma by flavonoids in mouse macrophages. FEBS Lett 496, 12-18.

20. Byun T, Karimi M, Marsh JL, Milovanovic T, Lin F \& Holcombe RF (2005) Expression of secreted Wnt antagonists in gastrointestinal tissues: potential role in stem cell homeostasis. J Clin Pathol 58, 515-519.

21. Gregorieff A \& Clevers H (2005) Wnt signaling in the intestinal epithelium: from endoderm to cancer. Genes Dev 19, 877-890.

22. Kundu JK, Choi K-Y \& Surh Y-J (2006) Beta-catenin-mediated sinalling: a novel molecular target for chemoprevention with anti-inflammatory substances. Biochimica et Biophysica Acta 1765, 14-24.

23. Park CH, Chang JY, Hahm ER, Park S, Kim HK \& Yang CH (2005) Quercetin, a potent inhibitor against beta-catenin/Tcf signaling in SW480 colon cancer cells. Biochem Biophys Res Commun 328, 227-234.

24. Hara H, Gee JM \& Johnson IT (1999) Antiproliferative effects of quercetin in the rat gastrointestinal tract. In Antiproliferative Effects of Quercetin in the Rat Gastrointestinal Tract, pp. 49-53 [A Krogdahl, SD Mathieson and IF Pryme, editors]. Brussels: European Commission.

25. Jaiswal AS, Marlow BP, Gupta N \& Narayan S (2002) Betacatenin-mediated transactivation and cell-cell adhesion pathways are important in curcumin (diferuylmethane)-induced growth arrest and apoptosis in colon cancer cells. Oncogene 21, 8414-8427.

26. Joe AK, Liu H, Suzui M, Vural ME, Xiao D \& Weinstein IB (2002) Resveratrol induces growth inhibition, S-phase arrest, apoptosis, and changes in biomarker expression in several human cancer cell lines. Clin Cancer Res 8, 893-903.

27. Agullo G, Gamet-Payrastre L, Fernandez Y, Anciaux N, Demigne C \& Remesy C (1996) Comparative effects of flavonoids on the growth, viability and metabolism of a colonic adenocarcinoma cell line (HT29 cells). Cancer Lett 105, 61-70.

28. Wenzel U, Kuntz S, Brendel MD \& Daniel H (2000) Dietary flavone is a potent apoptosis inducer in human colon carcinoma cells. Cancer Res 60, 3823-3831.

29. Kim MJ, Kim DH, Na HK, Oh TY, Shin CY \& Surh Ph DPYJ (2005) Eupatilin, a pharmacologically active flavone derived from Artemisia plants, induces apoptosis in human gastric cancer (AGS) cells. J Environ Pathol Toxicol Oncol 24, $261-269$.

30. Musk SR, Stephenson P, Smith TK, Stening P, Fyfe D \& Johnson IT (1995) Selective toxicity of compounds naturally present in food toward the transformed phenotype of humancolorectal cell line HT29. Nutr Cancer 24, 289-298. 
31. Winawer SJ (1999) Natural history of colorectal cancer. Am J Med 106, 3S-6S, discussion 50S-51S.

32. Vogelstein B, Fearon ER, Hamilton SR, Kern SE, Preisinger AC, Leppert M, Nakamura Y, White R, Smits AM \& Bos JL (1988) Genetic alterations during colorectal-tumor development. $N$ Engl J Med 319, 525-532.

33. Jubb AM, Bell SM \& Quirke P (2001) Methylation and colorectal cancer. J Pathol 195, 111-134.

34. Bestor TH (1998) Gene silencing. Methylation meets acetylation. Nature 393, 311-312.

35. Esteller M, Corn PG, Baylin SB \& Herman JG (2001) A gene hypermethylation profile of human cancer. Cancer Res 61, $3225-3229$.

36. Issa JP (2000) The epigenetics of colorectal cancer. Ann NY Acad Sci 910, 140-153.

37. Lin J, Zhang SM, Wu K, Willett WC, Fuchs CS \& Giovannucci E (2006) Flavonoid intake and colorectal cancer risk in men and women. Am J Epidemiol 164, 644-651.

38. Lodovici M, Casalini C, De Filippo C, Copeland E, Xu X, Clifford M \& Dolara P (2000) Inhibition of 1,2-dimethylhydrazineinduced oxidative DNA damage in rat colon mucosa by black tea complex polyphenols. Food Chem Toxicol 38, 1085-1088.

39. Sengupta A, Ghosh S \& Das S (2003) Tea can protect against aberrant crypt foci formation during azoxymethane induced rat colon carcinogenesis. J Exp Clin Cancer Res 22, 185-191.

40. Ogasawara M, Matsunaga T \& Suzuki H (2007) Differential effects of antioxidants on the in vitro invasion, growth and lung metastasis of murine colon cancer cells. Biol Pharm Bull 30, 200-204

41. Orner GA, Dashwood WM, Blum CA, Diaz GD, Li Q \& Dashwood RH (2003) Suppression of tumorigenesis in the $\mathrm{Apc}(\mathrm{min})$ mouse: down-regulation of beta-catenin signaling by a combination of tea plus sulindac. Carcinogenesis 24, $263-267$.

42. Ju J, Hong J, Zhou JN, Pan Z, Bose M, Liao J, Yang GY, Liu YY, Hou Z, Lin Y, Ma J, Shih WJ, Carothers AM \& Yang CS (2005) Inhibition of intestinal tumorigenesis in Apcmin/+ mice by (-)-epigallocatechin-3-gallate, the major catechin in green tea. Cancer Res 65, 10623-10631.

43. Sun CL, Yuan JM, Koh WP \& Yu MC (2006) Green tea, black tea and colorectal cancer risk: a meta-analysis of epidemiologic studies. Carcinogenesis 27, 1301-1309.

44. Dolara P, Luceri C, Filippo CD, Femia AP, Giovannelli L, Caderni G, Cecchini C, Silvi S, Orpianesi C \& Cresci A (2005) Red wine polyphenols influence carcinogenesis, intestinal microflora, oxidative damage and gene expression profiles of colonic mucosa in F344 rats. Mutat Res 591, 237-246.

45. Lauren P (1965) The two histological main types of gastric carcinoma: diffuse and so-called intestinal-type carcinoma. Acta Pathol Microbiol Scand 64, 31-49.

46. Crew KD \& Neugut AI (2006) Epidemiology of gastric cancer. World J Gastroenterol 12, 354-362.

47. Peek RM Jr \& Blaser MJ (2002) Helicobacter pylori and gastrointestinal tract adenocarcinomas. Nat Rev Cancer 2, 28-37.

48. Correa P (1992) Human gastric carcinogenesis: a multistep and multifactorial process. Cancer Res 52, 6735-6740.

49. Huang JQ, Sridhar S, Chen Y \& Hunt RH (1998) Meta-analysis of the relationship between Helicobacter pylori seropositivity and gastric cancer. Gastroenterology 114, 1169-1179.

50. Ruggiero P, Tombola F, Rossi G, Pancotto L, Lauretti L, Del Giudice G \& Zoratti M (2006) Polyphenols reduce gastritis induced by Helicobacter pylori infection or VacA toxin administration in mice. Antimicrob Agents Chemother 50, 2550-2552.

51. Yoshida M, Sakai T, Hosokawa N, Marui N, Matsumoto K, Fujioka A, Nishino H \& Aoike A (1990) The effect of quercetin on cell cycle progression and growth of human gastric cancer cells. FEBS Lett 260, 10-13.
52. Yoshimizu N, Otani Y, Saikawa Y, Kubota T, Yoshida M, Furukawa T, Kumai K, Kameyama K, Fujii M, Yano M, Sato T, Ito A \& Kitajima M (2004) Anti-tumour effects of nobiletin, a citrus flavonoid, on gastric cancer include: antiproliferative effects, induction of apoptosis and cell cycle deregulation. Aliment Pharmacol Ther 20, Suppl 1, 95-101.

53. Sun CL, Yuan JM, Lee MJ, Yang CS, Gao YT, Ross RK \& Yu MC (2002) Urinary tea polyphenols in relation to gastric and esophageal cancers: a prospective study of men in Shanghai, China. Carcinogenesis 23, 1497-1503.

54. Lagiou P, Samoli E, Lagiou A, Peterson J, Tzonou A, Dwyer J \& Trichopoulos D (2004) Flavonoids, vitamin C and adenocarcinoma of the stomach. Cancer Causes Control 15, 67-72.

55. Gaspar J, Laires A, Monteiro M, Laureano O, Ramos E \& Rueff J (1993) Quercetin and the mutagenicity of wines. Mutagenesis $8,51-55$.

56. Ferlay J, Bray F, Pisani P \& Parkin DM (2001) IARC Cancer Base No. 5, GLOBOCAN 2000: Cancer Incidence, Mortality and Prevalence Worldwide. Lyon: IARC.

57. Roth MJ, Strickland KL, Wang GQ, Rothman N, Greenberg A \& Dawsey SM (1998) High levels of carcinogenic polycyclic aromatic hydrocarbons present within food from Linxian, China may contribute to that region's high incidence of oesophageal cancer. Eur J Cancer 34, 757-758.

58. Newnham A, Quinn MJ, Babb P, Kang JY \& Majeed A (2003) Trends in the subsite and morphology of oesophageal and gastric cancer in England and Wales 1971-1998. Aliment Pharmacol Ther 17, 665-676.

59. Prach AT, MacDonald TA, Hopwood DA \& Johnston DA (1997) Increasing incidence of Barrett's oesophagus: education, enthusiasm, or epidemiology? Lancet 350, 933.

60. Wild CP \& Hardie LJ (2003) Reflux, Barrett's oesophagus and adenocarcinoma: burning questions. Nat Rev Cancer 3, 676-684.

61. Lagergren J, Bergstrom R, Lindgren A \& Nyren O (1999) Symptomatic gastroesophageal reflux as a risk factor for esophageal adenocarcinoma. $N$ Engl J Med 340, 825-831.

62. Lagergren J, Bergstrom R \& Nyren O (1999) Association between body mass and adenocarcinoma of the esophagus and gastric cardia. Ann Intern Med 130, 883-890.

63. Bosetti C, La Vecchia C, Talamini R, Simonato L, Zambon P, Negri E, Trichopoulos D, Lagiou P, Bardini R \& Franceschi S (2000) Food groups and risk of squamous cell esophageal cancer in northern Italy. Int J Cancer 87, 289-294.

64. Zhao Y, Cao J, Ma H \& Liu J (1997) Apoptosis induced by tea polyphenols in HL-60 cells. Cancer Lett 121, 163-167.

65. Engel LS, Chow WH, Vaughan TL, Gammon MD, Risch HA, Stanford JL, Schoenberg JB, Mayne ST, Dubrow R, Rotterdam $\mathrm{H}$, West AB, Blaser M, Blot WJ, Gail MH \& Fraumeni JF Jr (2003) Population attributable risks of esophageal and gastric cancers. J Natl Cancer Inst 95, 1404-1413.

66. Liang YC, Huang YT, Tsai SH, Lin-Shiau SY, Chen CF \& Lin JK (1999) Suppression of inducible cyclooxygenase and inducible nitric oxide synthase by apigenin and related flavonoids in mouse macrophages. Carcinogenesis 20, 1945-1952.

67. O'Leary KA, de Pascual-Tereasa S, Needs PW, Bao YP, O'Brien NM \& Williamson G (2004) Effect of flavonoids and vitamin $\mathrm{E}$ on cyclooxygenase-2 (COX-2) transcription. Mutat Res 551, 245-254.

68. Cheong E, Ivory K, Doleman J, Parker ML, Rhodes M \& Johnson IT (2004) Synthetic and naturally occurring COX-2 inhibitors suppress proliferation in a human oesophageal adenocarcinoma cell line (OE33) by inducing apoptosis and cell cycle arrest. Carcinogenesis 25, 1945-1952.

69. Li ZG, Shimada Y, Sato F, Maeda M, Itami A, Kaganoi J, Komoto I, Kawabe A \& Imamura M (2002) Inhibitory effects 
of epigallocatechin-3-gallate on N-nitrosomethylbenzylamineinduced esophageal tumorigenesis in F344 rats. Int $J$ Oncol 21, 1275-1283.

70. Nie Y, Liao J, Zhao X, Song Y, Yang GY, Wang LD \& Yang CS (2002) Detection of multiple gene hypermethylation in the development of esophageal squamous cell carcinoma. Carcinogenesis 23, 1713-1720.

71. Fang MZ, Wang Y, Ai N, Hou Z, Sun Y, Lu H, Welsh W \& Yang CS (2003) Tea polyphenol (-)-epigallocatechin-3gallate inhibits DNA methyltransferase and reactivates methylation-silenced genes in cancer cell lines. Cancer Res 63, $7563-7570$.

72. Fang MZ, Jin Z, Wang Y, Liao J, Yang GY, Wang LD \& Yang CS (2005) Promoter hypermethylation and inactivation of $\mathrm{O}(6)$-methylguanine-DNA methyltransferase in esophageal squamous cell carcinomas and its reactivation in cell lines. Int J Oncol 26, 615-622.

73. Carlson BA, Dubay MM, Sausville EA, Brizuela L \& Worland PJ (1996) Flavopiridol induces G1 arrest with inhibition of cyclin-dependent kinase (CDK) 2 and CDK4 in human breast carcinoma cells. Cancer Res 56, 2973-2978.

74. Schrump DS, Matthews W, Chen GA, Mixon A \& Altorki NK (1998) Flavopiridol mediates cell cycle arrest and apoptosis in esophageal cancer cells. Clin Cancer Res 4, 2885-2890.
75. Blagosklonny MV (2004) Flavopiridol, an inhibitor of transcription: implications, problems and solutions. Cell Cycle 3, $1537-1542$.

76. Raju U, Ariga H, Koto M, Lu X, Pickett J, Valdecanas D, Mason KA \& Milas L (2006) Improvement of esophageal adenocarcinoma cell and xenograft responses to radiation by targeting cyclin-dependent kinases. Radiother Oncol 80, 185-191.

77. Sato S, Kajiyama Y, Sugano M, Iwanuma Y \& Tsurumaru M (2004) Flavopiridol as a radio-sensitizer for esophageal cancer cell lines. Dis Esophagus 17, 338-344.

78. Cooke DN, Thomasset S, Boocock DJ, Schwarz M, Winterhalter P, Steward WP, Gescher AJ \& Marczylo TH (2006) Development of analyses by high-performance liquid chromatography and liquid chromatography/tandem mass spectrometry of bilberry (Vaccinium myrtilus) anthocyanins in human plasma and urine. J Agric Food Chem 54, 7009-7013.

79. Ranka S, Gee JM, Biro L, Brett G, Saha S, Kroon P, Skinner J, Hart AR, Cassidy A, Rhodes M \& Johnson IT (2007) Development of a food frequency questionnaire for the assessment of quercetin and naringenin intake. Eur J Clin Nutr (Epub ahead of print 30 May 2007)

80. Shapiro H, Singer P, Halpern Z \& Bruck R (2007) Polyphenols in the treatment of inflammatory bowel disease and acute pancreatitis. Gut 56, 426-436. 